located in the upper part of the ascending frontal convolution on the right side, and on the posterior end of the second frontal convolution of the same side. Probably the other side of the brain was also affected, and this will account for the cross symptoms the case presented. The friends stated to me that he fell on the right side of the head, but shaving the scalp disclosed the recent scar on the left side. It was the crossed condition which determined us to trephine at the seat of injury rather than at the point of physiological disturbance; and I was the more inclined to do this because I remembered to have seen cases of supposed occipital concussion productive of considerable mental confusion and irregular, almost choreic, movements. The relief afforded by the operation was too full to admit of doubt that it played the only part in the recovery, although nothing was discovered at the seat of injury. What the operation did was manifestly to relieve tension, and thus the compression. In future, unless the apparent seat of injury corresponds with the symptoms produced, I shall trephine over the centres involved rather than the neighhood of the wound. Had I followed this physiological law instead of the old surgical axiom the result from an operative point of view would have been satisfactory, whereas now it is only interesting and negative.

Since writing the above I have seen the patient, who is quite well in every respect.

Macclesfield.

\section{PUERPERAL FEVER: A POSSIBLE SOURCE OF CONTAGION.}

By R. D. PEDLEY, F.R.C.S. ED. AND L.D.S.,

DENTAL SURGEON TO THE EVELINA HOSPITAL FOR SICK CHILOREN, SOUTHWARK ; ASSISTANT DENTAL SURGEON TO THE NATIONAL DENTAL HOSPITAL.

Is it possible for a medical practitioner or a nurse whose mouth is in an unhealthy condition to be the means of developing in a patient puerperal fever or any of the local manifestations of septic poisoning, such as pelvic cellulitis or pelvie peritonitis? This question has many times presented itself since reading as a student a case mentioned by Dr. Playfair in vol. ii. of "The Science and Practice of Midwifery," of a medical man who, suffering from chronic ozæna, had to relinquish practice on account of the numerous deaths from puerperal fever among his patients. I have not been able to answer the above question in the affirmative, but I consider there is sufficient evidence to justify a few remarks, thereby placing the matter before those who have better opportunities of forming a correct judgment. Some light may be thrown on this "possible source of contagion" by making mention of a case recently reported in the daily press of an inquest held on the body of a woman who had died from puerperal fever. The mother of the patient-an uncertified midwife-had been the means of spreading this terrible disease. Dr. Talbot, in evidence, stated that "he had attended her for a piece of dead bone in the mouth, and if she had been fingering it that might account for the outbreak." This, of course, is an extreme case. Probably the woman was suffering from syphilitic necrosis, and that her mouth was in a very bad condition, also that her acquaintance with antiseptics was practically nil. Most mouths are rendered foul by carious teeth, and there can be very little doubt that medical men and nurses are as liable to suffer from carious teeth as their patients, and find, as a rule, far less opportunity of seeking attention.

The condition $I$ refer to is generally brought about as follows. A tooth is attacked by caries. If neglected this makes its way into the tooth until the pulp chamber is reached, and the nerve is exposed. After a variable amount of pain the nerve dies, and becomes putrid right up to the apex of the fang. A small amount of septic matter escapes through the apical foramen, and sets up an acute alveolar abscess. At this stage if the tooth is extracted the trouble is ended; but if the pus is let out beneath the lip, or makes its way through the thin alveolar plate, the swelling disappears after a day or two and a sinus remains from which matter is constantly dis charged in small quantities. In dental ianguage it becomes a chronic alveolar abscess. The tooth is practically a piecs of dead bone; with this difference, that through its centre is a narrow channel in which rests the remains of a putrid nerve. It is quite common to find several teeth in a similar. condition, sometimes cut down level with the gum, having received no further treatment than careful concealment by artificial teeth. Beyond the fact that an occasional swelling takes place in the alveolar plate, and a very disagreeable taste is present, the owner may go on for years with very little discomfort. Is it unreasonable to suppose that a very intelligent nurse (having several teeth such as we have described) may seek to relieve the pain of an aching stump by pressure of the fingers; and, not being aware of any danger, convey septic matter to the body of the patient in the ordinary discharge of her duties?

In May and September of 1886 two cases came under nay notice, of which brief notes were taken at the time.

C.ISE 1.-Miss —-, a nurse, said she should have been before, but had been attending a case of puerperal fever. Her month was in an unwholesome condition. Front teeth good. Not a single molar sound ; all the back teeth carious. Had two alveolar abscesses in connexion with upper bicuspid teeth on the right side, and one in connexion with a lover molar tooth on the left side.

C $\Lambda$ SE 2.-Dr. abscess over left lateral incisor tooth in the upper jaw. Faee considerably swollen. Tooth had been sore for some time; he could scarcely bite anything with comfort. Teeth generally in a bad condition. Several stumps in the lower jaw on the right side and in the upper jaw on the left side. Had suffered for years; of late the stumps had given considerable trouble. Several sinuses from which pus oozed. Would have sought advice before, but just after tooth became troublesome had a puerperal fever case to attend to, and had been much worried. No reason to be assigned for puerperal fever; surroundings good and healthy. Good drainage.

That pus from an alveolar abscess is necessarily septic we cannot be sure; but there are three facts worthy of notice: 1. Pus from an alveolar abscess is often of foul odour. 2. As a consequence of alveolar abscess, necrosis of a portion of the jaw-bone is not at all unconmon. 3. There are cases recorded of patients who have died from pyrmia and septicemia as the result of alveolar abscess, wide Tomes' "Dental Surgery," Salter's "Dental Pathology and Surgery."

It may be urged that the medical practitioner is con. stantly brought in contact with septic matter, and that the adoption of the necessary antiseptic precautions would exclude all possibility of such direct communication as I have suggested. This is quite likely; also that, if a source of danger is pointed out, the medical man may be trusted to do his best to aroid it. We cannot be so sure of the nurse, who necessarily is bronght far more often in contact with the patient, and who, after the first few hours, has the wellbeing of the patient in her own hands. No medical man curn be held responsible should the nurse fail to carry out his instructions; but he can, in most cases, ascertain beforehand that the nurse is not the subject of a malady, be it local or constitutional, which is likely to be a source of danger to his patient. In conclusion, I would offer this brief suorestion. It is desirable that midwives and nurses should be snbjected to medieal inspection before attending obstetric cases.

Railway Appronch, London Bridses, S. F.

\section{TRANSVERSE SEPTUM IN THE VAGINA TREATED BY OPEPATION.}

BY CHAS. R. PRANCE, M.D., F.R.C.P.L., SINUOR PHYSICTAN TO THE SOUTII UEVON AND ESST CORNWALL HOSPTYAL,

Ix TIIE LANCEr of April 13th, Dr. C. J. Cullingworth reported on cases of transverse septum in the vagina which he had treated successfully. I was rather surprised to see in the bibliography appended to that paper how comparatively few cases had been recorded, and yet many sueh min:t occur, and it may be well to add to the record. It so happened that within one week in March last two such cases came under my care, and others, though not quile of the same kind, at various periods before. Of the two 
Lately occurring, in one-a young unmarried lady of twentyfive-I was actually consulted by her mother about her as suffering from menorrhagia and dysmenorrhoea; and yet, on digival examination, the septum (or diaphragm, which I think is a more accurate term) was so complete that I could with the finger detect no aperture in it, though doubtless there was some minute orifice, but so minute ss to render the process of evacuation of the menstrual fluid a long-continued affair. I regret that in consequence of the removal of this patient with her family at that time from the town to a distance, I was unable to follow up the case for more careful investigation and further treatment.

The other case was that of a lady, aged thirty-two, who had been married nearly three years, and who was said to menstruate regularly and without any noticeable difficulty; there had been no pregnancy. The occasion of my being consulted was for general debility and various nervous symptoms and depression. In the absence of impregnation, and from her answers to questions suggested by that, the doubt occurred to my mind whether, notwithstanding the menstruation, there might not exist some mechanical obstacle to efficient intercourse. Digital examination revealed such an obstacle; one felt-as in the case mentioned before-only a sort of thimble-shaped cavity with a sufficiently wide opening, but apparently absolutely closed top; and per rectum I could feel higher up that the cervix and body of the uterus were of ordinary size. This being the case, I suggested an operation, and the surgical assistance of $\mathrm{Mr}$. Connell Whipple, of this town, was called in. We together carefully examined her in a good light. The diaphragm was a fleshy one, of the same reddish colour as the parts around, with rather roughish surface, having some small fleshy papillary projections. We failed to detect any aperture, and the problem as to whether she really menstruated, or had some vicarious discharge which took its place, could only be solved by waiting until the next menstrual period. In rather less than three weeks we received notice that this had come on, when we met again. On examination, there was no menstrual fluid to be seen, and the only apparent change was that the thimble-cavity was much shallower and the top slightly bulged down. She was then directed to strain downwards; there was at once seen a small oozing of the menstrual fluid from the anterior part of the membrane, about one-third of an inch behind the urethral orifice- much as when one pricks with a pin an artist's bladder of oil paint,the minute aperture was at the base of and hidden by one of the afore-mentioned papillæ. Mr. Whipple barely succeeded in passing a fine eye probe through it; an ordinary silver probe would not pass. This fine probe was then felt to move freely in the cavity of an ample vagina beyond, its point could also be felt by the finger per rectum, and the uterus above. The diagnosis being now clear, and operative interference justified, we waited six or seven days until the discharge had quite ceased. We then met again, and Mr. Whipple proceeded to operate. The patient being under methylene and placed in the lithotomy position, and the pinhole orifice having with a little difficulty been again found, it was dilated enongh to allow the passage of a director, and on that a bistoury, with which the fleshy membrane was incised crucially; then the quarters were removed by means of scissors back to the level of the vaginal wall, so as to leave no projection. The homorrhage was trifling. The vagina was then well syringed out with a carbolised injection, which process was repeated daily thereafter by the nurse during healing. The vagina was now fully patent, would admit two fingers easily its whole length, and the os, cervix, and uterus felt normally developed. The patency was secured by the daily introduction, until healing was complete, of a good-sized finger-shaped wad of compressed cotton wool, smeared with vaseline, and the patient was kept in bed. In a few days she was quite well, and restored to her busband with a patent vagina, and I may add soon became pregnant. This is a different kind of case from that of an absolutely imperforate diaphragm, which I have also met with, and which is more common, and also other cases which I have encountered of circular dense hymen with a comparatively small central opening. The former reveals itself by entire absence of menstruation, and the suprapubic tumour is formed by gradual accumulation; but in such a case as the one detailed above, a fruitless married life may go on, uncomplained of obstruc tion, however strange it may seem, and menstruation go on regularly; so that there is no suspicion of the real state of malformation, until it may so happen that, the woman consulting a medical man, but not for that special purpose, circumstances suggesting suspicion may fortunately lead to an examination, and the state of affairs is revealed and safely remedied. One can hardly think of any malformation possibly involving momentous issues in family history, yet so readily set right, and with such satisfactory results. A caution, however, with regard to operative procedure in these cases suggests itself from my remembrance of another very different, though outwardly similar, kind of case, about a well-grown handsome young lady of marriageable age, who had never menstruated. On examination I found the same short, thimble-shaped cul-de-sac vagina, but on the most careful examination per rectum and above the pubes I could detect no uterus, and gave my opinion that there was none, and that no operation was advisable or feasible. She was afterwards taken by her parents to con sult a specialist in London, who absolutely confirmed my opinion of the melancholy fact as one incapable of remedy. Plymouth.

\section{A CASE IN WHICH PERITONITIS WAS CAUSED BY VAGINAL SYRINGING AFTER TWO SUCCESSIVE CONFINEMENTS.}

\section{BY CHARLES SCOTT WATSON, M.D.}

Mrs. A. B-, a healthy primipara, was confined on Aug. 18th, 1886, after an easy and natural labour. Vaginal syringing night and morning with dilute Condy's fluid was ordered, and a Higginson's syringe was used for the purpose. All went well---pulse and temperature keeping below normal-for thirty-six hours-i.e., till 6 P.M. on the 19th, when, immediately after being syringed, the patient turned on her left side and was at once seized with severe pain in the left iliac fossa, soon spreading across the lower abdomen. Shortly afterwards she had a rigor, and the temperature rose to $1034^{\circ}$, the pulse to 110 . At my visit about 7 P.M. she was lying on her back in great distress, complaining of intense constant pain and of tenderness over the lower half of the abdomen. Both pain and tenderness were most severe in the left iliac region. Abdominal examination, as far as it could be carried out for the tenderness and resistance, disclosed nothing abnormal, and no vaginal examination was then made. About midnight the pain began to abate a little, but did not disappear till the 21st, when also the temperature fell to normal. On that date there was still abdominal tenderness, and on vaginal examination the uterus and vaginal roof were found to be tender, the uterus not freely movable, but not displaced. On the 22nd a dose of castor oil was given, apparently a mistake in the management of the case; for on the following day there was a gradual return of pain and tenderness (rather more diffused than in the first attack) and of fever, the temperature rising to $101^{\circ}$ and the pulse to 100 on the evening of the $23 \mathrm{rd}$. Under opium and poultices these symptoms again yielded, and on the 25 th there was neither pain, tenderness, nor fever. From the 29 th to the 31 st the temperature ranged between $100^{\circ}$ and $104^{\circ}$, in association with pain and tenderness in different areas of the breasts. On the latter date the uterus was well reduced in size, movable, not tender, the vagina everywhere soft and painless. Thereafter the patient did well. Her second confinement, again in every respect natural, took place on April 5th, 1888 . Vaginal syringing ( 1 in 3000 sublimate) was again carried out twice daily with a Higginson's syringe. The patient made satisfactory progress up to the morning of the $17 \mathrm{th}$, the highest temperature registered being $984^{\circ}$, the highest pulse 72 . She got up on the eleventh day, and again on the twelfth. On the morning of the $17 \mathrm{th}-$ i.e., twelve days and a half after confinement-when syringing was being carried out the same accident again occurred. The patient was on her back, and had passed the vaginal tube herself without any pain or unusual feeling. After two syringefuls had been gently delivered, and while the fluid was returning clear, and apparently as freely as usual, she felt pain in the left iliac fossa. The pain rapidly increased, and after five or six syringefuls the patient felt very sick, and syringing was stopped. She then turned on her left side, when 